\title{
The Problems in Speaking for English Department Student in STKIP BUDIDAYA - BINJAI
}

\author{
Ayu Indari, S. Pd. I, M. Hum \\ English Lecturer - English Department Student STKIP Budidaya Binjai \\ a.indari@gmail.com
}

\begin{abstract}
This paper is purposed to find out the problems in speaking skills for English department student in STKIP Budidaya - Binjai. The speaking skill is the last position to cover up the four skills in English because speaking is the improving your ability to use four skills in English. Speaking needs some stimulation to attract the students speaks their ideas, opinion, or comments about something. The sample of the study is the third students in English department student, it is around 28 students. The data are collected through document by sound recording. The data analyzed by using the technique of analyze data. The result of the study is that it concludes that first question "What is the problem of speaking?" 10 students $(35,71 \%)$ respond less of confident and 10 students $(35,71 \%)$ respond less of vocabulary. The second question "How the ways do you practice your speaking skill?" 10 students $(35,71 \%)$ respond watching movie. The third question "Do you agree that speaking is the most difficult to study comparing with another skills in English? And why?" 18 students $(64,29 \%)$ respond yes, because it takes orally.
\end{abstract}

Keywords: Speaking Skills, Speaking Problem

\section{INTRODUCTION}

Speaking is one of the skills which is studied in English. It is the most unique skills to learn because it takes a special treatment to conduct. Reading skill focusses on the text and reading comprehension to be able about the vocabulary and the information including the text. Listening skill takes the sound and specific information delivering by audio; it needs to catch the information by audio carefully in the limited time. Writing skill is the way to express the capability to inform the information in written text. It needs the creativity managing the word or sentences. Finally speaking skill is the last position to cover up the four skills in English because speaking is the improving your ability to use four skills in English. Speaking needs some stimulation to attract the students speaks their ideas, opinion, or comments about something.

In addition, speaking is the process of building and sharing meaning through the use of verbal and non-verbal symbols. Speaking is a crucial part of foreign language learning and teaching. Despite of its importance for many years, teaching speaking has been undervalued and English language teachers have continued to teach speaking just as a repetition of drills or memorization of dialogues. However, today's 
world requires that the goal of teaching speaking should improve students; communicative skills, because only in that way the students can express themselves and learn how to follow the social and cultural rules appropriate in each communicative circumstance (Kartika, 2016: 1).

Most teachers, in many different learning cultures, have moments when their students fail to cooperate in some way, thus disrupting the learning which should be taking place, sometimes getting significantly 'out of control'. Such moments of disruption can be unsettling not just for teachers but also students (Harmer, Jeremy, 2003:126).

Problem behavior can take many forms; Paul Waddon and Sean McGovern list disruptive talking, inaudible responses, sleeping in class, tardiness and poor attendance, failure to do homework, cheating in tests and unwillingness to speak in the target language ( Wadden and McGovern, 1991). Of course their list may reflect the educational culture where they were teaching rather than being universal. In bullying other students, damaging school property, and refusing to accept sanction or punishment. However, what is characterized as indisipline '.... depends on what counts as well-ordered or disciplined classroom for the individual teacher' (Brown and McIntyre, 1993:44).

\section{RESEARCH METHODOLOGY}

\section{Research Design}

This paper applies content analysis method. Krippendorf (2004: 18) says that content analysis is a research technique for making replicable and valid inferences from texts (or other meaningful matter) to the contexts of their use. The reference to text in the above definition is not intended to restrict content analysis to written material. The phrase "or other meaningful matter" is included in parentheses to indicate that in content analysis works of the images, maps, sounds, signs, symbols, and even numerical records may be included as data that is, they may be considered as texts-provided they speaks to someone about phenomena outside of what can be sensed or observed. This paper takes a sound recording to be as a data analysis.

\section{Data Source}

The sources of data are third semester students in English department in STKIP Budidaya, namely III A and III B. It consists of 28 students. From the problem of the study, it concludes that the paper instrument is using document which is sound recording.

\section{Technique of Collecting Data}

The data are collected through document by sound recording. The data are done on 22 october 2019. The data take 3 questions to the students as a question for mid test and they are collected by recording.

\section{Technique of Data Analysis}

After gathering data from sources including documentation and collecting the data; the data analyzed by using the technique of analyze data. The technique of analysis defines what kind of information may or may not endow of the various information within data obtained. Technique of data analysis in this paper is used to find out the problems in speaking skills.

\section{RESEARCH FINDING AND DISCUSSION}




\section{Research Finding}

In analyzing the data, this paper follows the data analysis. The data mention some problems in speaking skills. The categories of the questions are:

1. What is the problem of speaking?

2. How the ways do you practice your speaking skill?

3. Do you agree that speaking is the most difficult to study comparing with another skills in English? And why?

From this category of the questions, the data conclude that:

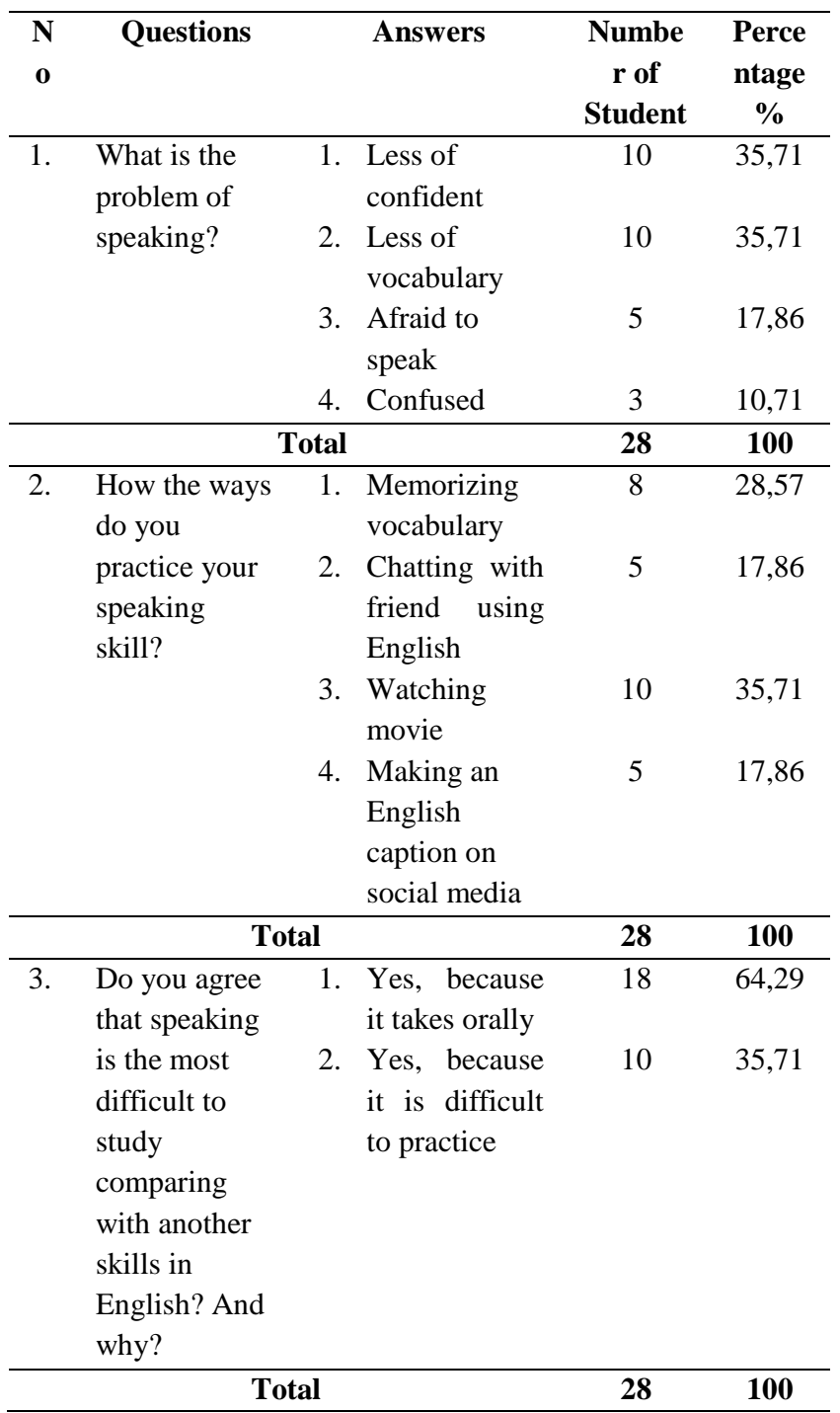

From the table above, it concludes that first question "What is the problem of speaking?" 10 students $(35,71 \%)$ respond less of confident and 10 students $(35,71 \%)$ respond less of vocabulary. The second question "How the ways do you practice your speaking skill?" 10 students $(35,71 \%)$ respond watching movie. The third question "Do you agree that speaking is the most difficult to study comparing with another skills in English? And why?" 18 students (64,29\%) respond yes, because it takes orally.

\section{Discussion}

\section{A. Why Problems Occur}

There are many reasons for problem behavior. It can stem from a student's reactions to their teacher's behavior, from other factors inside the classroom, or from outside factors:

1). The family: students' experiences in their families have a profound influence on their attitudes to learning and to authority. Sometimes indiscipline can be traced back to a difficult home situation. Sometimes home attitudes to English, to learning in general, or even to teachers themselves can predispose students to behave problematically.

2). Education: previous learning experiences of all kinds affect students' behavior. Even at the level of the last teacher let me...., students are influenced by what went before, and their expectations of the learning experience can be coloured either by unpleasant memories, or by what they were once allowed to get away with.

3). Self-esteem: a student's self-esteem is vitally important if effective learning is to take place. Self-esteem may result partly from teacher approval (especially for children), from a 
student's peers (especially for adolescents), or as a result of success. A lack of respect from teacher or peers - or being asked to do something where they are almost certainly bound to fail - can make students feel frustrated and upset. In such a situation disruptive behavior is an attractive option. It can impress peers, and does, at least, force the teacher to take them seriously.

4). Boredom: when students are engaged with a task or a topic they are unlikely to behave disruptively. But if they lose that engagement they may misbehave. When pairs or groups finish early and are left unattended, boredom may lead to disruption; when the chosen topic or activity is inappropriate, students sometimes show their lack of interest by behaving badly.

5). External factors: some external factors may affect students' behavior too. If they are tired they will not be able to concentrate. If the classroom is too hot or too cold this may result in students being too relaxed or too nervy. Discomfort then leads to disengagement. Noise from outside the classroom can impact badly upon students' concentration.

Teachers at primary level, especially, notice significant behavior changes in different weathers, so that a high wind, in particular, tends to make their children 'go wild'.

6). What the teacher does: a lot will depend on how we behave in class, especially when problem behavior first takes place. Students who feel their self-esteem to have been damaged by the way we discipline them - especially if we appear unfair - are more likely to be badly behaved in the future.

\section{B. Preventing Problem Behavior}

There are a number of strategies that teachers can make use of to avoid problems occurring in the first place, because prevention is always better than the disciplining cure.

\section{1). Creating a code of conduct}

An important part of effective classroom management is for the students to 'know where they stand'. This is often done, with younger learners especially, by establishing a code of conduct - although in fact, such a code can be equally valid for use with unenthusiastic adult classes.

An effective way of establishing a code of conduct is to include the students' own opinions in the code; these will frequently be as responsible and forthright as anything a teacher might come up with. With a class of adults, for example, the teacher and students together can talk about a range of issue such as how often homework is expected, what a good learner is, attitudes to mistakes and feedback, and the use of their mother tongue. When a teacher and students have divergent views about what is acceptable and what is not, the teacher should take their opinions into account, but ultimately he or she will have to be firm about what he or she is prepared to accept. With low-level classes teachers may need to hold the discussion in the students' first language. Where this is not possible -as in a multilingual class - they will need to show quickly and calmly, through example, what is expected and what is not acceptable.

Some teachers adopt a formula where teacher and students produce a chart which says As your teacher/a learner I expect ...., As your teacher/a learner, I will .... This document can be put on the class noticeboard for all to see. Then, when students are disruptive or uncooperative, they can be referred to the code of conduct and expected to abide by rules and norms which they themselves agreed to. 
When a code has been thus democratically arrived at - with everyone having a say and coming to an argument - it has considerable power.

\section{2). Teachers and students}

Just as a teacher's behavior may itself sometimes be the cause of disruptive events, so the way we teach, and the relationship we have with students, can help to prevent problem behavior from ever occurring. In particular, maintaining our students' interest and relating to them in appropriate ways holds the key to this.

a. Interest and enthusiasm: students who are interested and enthusiastic do not generally exhibit problem behavior. When we plan our classes, therefore, we need to bear in mind the need for such qualities as flexibility and variety. We also need, for example, to think how we can engage students in a reading or listening text before starting detailed work on it; we need to do our best to introduce topics that are relevant to our students' experience.

Interest can be also be generated by a teacher's performance. There is no doubt that students can be engaged by the energy and enthusiasm of their teachers.

b. Professionalism: students generally respect teachers who show that they know what they are doing. This can be demonstrated not only by our knowledge of our subject, but also by evidence that we have invested time in thinking about planning our lesson.

Professionalism also means practicing what we preach. If we insist on students handling their homework in promptly; then marking it and giving it back promptly are also obligatory. If we berate students for coming to class late, we will have to be seen to arrive punctually ourselves.

We must not be seen to issue idle threats. It is no good saying If you do this again I will ... if we cannot or will not take the action we have promised.

c. Rapport between teachers and students: a critical aspect in the prevention of problem behavior is the rapport we have with our students. This can be greatly enhanced by making sure that we listen to what they say with interest, and that we look at them when we talk to them; we need to ensure that we do not only respond to the students at the front - or the more extrovert ones but that we try and work with all of the people in our class.

\section{Please Speak English!}

One thing that can drive teachers wild is when their students are apparently unwilling to use English in the classroom, especially during communicative activities. This is often seen as an example of student/teacher failure. After all, if students are not using English everyone is wasting their time. However, there are many understandable reasons why students revert to their own language in certain activities.

\section{1). Why students use the mother tongue in class}

A principal cause of this L1 use is the language required by the activity. If we ask beginners to have a free and fluent discussion about global warming, for example, we are asking them to do something which they are linguistically incapable of. Their only possible course of action, if they really want to say anything about 
the topic, is to use their own language. In other words the choice of task has made the use of L1 almost inevitable; students can hardly be blamed for this.

Another reason why students use their own language in the classroom is because it is an entirely natural thing to do; when we learn a foreign language we use translation almost without thinking about it, particularly at elementary and intermediate levels. This is because we try to make sense of a new linguistic (and conceptual) world through the linguistic world we are already familiar with. Code switching between L1 and L2 is naturally developmental (Eldridge, 1996: 310), and not some example of misguided behavior.

Students use their L1 when performing pedagogical tasks, especially when one student is explaining something to another. This is a habit 'that in most cases will occur without encouragement from the teacher' ( Harbord, 1992: 354).

Another cause of mother tongue use can be teachers themselves. If, they frequently use the students' language (whether or not they themselves are native speakers of that language), then the students will feel comfortable doing it too. Teachers need, therefore, to be aware of kind of example they themselves are providing.

Finally, it is worth pointing out that the amount of L1 use by particular students may well have a lot to do with differing learner styles and abilities. Some use mostly English from the very beginning, whereas others seem to need to use their L1 more frequently.

2). Attitudes to mother tongue use in the classroom
The idea that all use of the mother tongue in the language classroom should be avoided stems from the advent of the Direct Method at the beginning of the twentieth century (where the language itself was talked and taught rather than being talked about in the students' L1), and from the training of native-English speaker teachers who either had to deal with multilingual classes and/or teach in countries before they were themselves competent in the language of their students.

More recently; however, attitudes to use of the students' mother tongue have undergone a significant change. David Atkinson argued that 'it is not difficult to think of several general advantages of judicious use of the mother tongue' (Atkinson, 1987: 242), suggesting that such activities as grammar explanations, checking for sense fell into this category. If teachers can use the students' language, he claims, these tasks will be expedited more efficiently.

This view is not shared, however, by Peter Harbord who points out that the giving of instructions and many other teacher-student interactions are 'an ideal source of language for student acquisition' (Harbord, 1992: 353).

No one is any doubt that students will use their L1 in class, whatever teachers say or do; the question is whether we should try and stop it. John Eldridge thinks not, suggesting that there is no evidence to suggest that this would improve learning efficiency. He claims that most of the code-switching he has observed is 'highly purposeful, and related to purposeful goals' (Eldridge, 1996: 303). 
Two issues seem to arise here. In the first place since students are likely to use their L1 anyway, there is little point in trying to stamp it out completely. Such an approach will not work, and may only discourage the students who feel the need for it at some stages. However, a lot will depend on when students use their L1. If they are working in pairs studying a reading text, for example, the use of their L1 may be quite acceptable since they are using it to further their understanding of English. If, on the other hand, they are doing an oral fluency activity; the use of a language other than English makes the activity essentially pointless. Furthermore, as teachers we will want to promote as much English use as possible. Do we will try and insist on the use of English in language study and oral production activities, but be more relaxed about it in other pedagogic situations, though we will continue to encourage students to try to use it as often as possible.

As for teachers, they are a principal source of comprehensible input; teacher-talking time (TTT) has an important part to play in language acquisition. It therefore makes sense for us to speak English as much as possible in the class, especially since if we do not, students will not see the need to speak too much English either. However there are times, especially at lower levels, where the use of L1 may help both teacher and students such as in an explanation or discussion of methodology, or the giving of announcements which would be impossibly difficult in English.

\section{3). What to do about it}

There are a number of actions which teachers can take to promote the use of English and explain clearly what is expected of students: a. Set clear guidelines: students need to know when mother tongue use is permissible and when it is not. Part of the agreed code of conduct with a class will be just this understanding of when it is more or less 'okay' and when it is seriously counterproductive. Students need to be aware of when English is absolutely essential. As with other issues in the code, our own adherence to it will be vital if it is to succeed.

b. Choose appropriate tasks: we should choose tasks which the students, at their level, are capable of doing in English. while there is nothing wrong in 'stretching' them with challenging activities which engage them, it is clearly counter-productive to set them tasks they are unable to perform.

c. Create an English atmosphere: if we create an English environment, making English the classroom language as well as the language to be learnt, and perhaps even anglicizing our students' names, then there will be more chance of the students making the classroom truly English themselves.

d. Use persuasion and other inducements: teachers all over the world spend a lot of their time going round to students, especially during speaking activities, saying things like, Please speak English! or Stop using Turkish/Arabic/Portuguese/Greek, etc. and it often works! If it does not, we can stop the activity and tell students there is a problem. This sometimes changes the atmosphere so that they go back to the activity with a new determination.

One teacher I knew used to make students pay a fine if they used the mother tongue in speaking activities, a course of action not recommended for the faint-hearted! But however 
it is done - the art of persuading students to have a go in English depends on the guidelines that were set, the argument we made with them, and the friendly encouragement and persuasion we use while activities are taking place. This, together with other measures that have been suggested, generally ensures that most students are speaking English most of the time.

\section{CONCLUSION}

After analyzing the data, the conclusion based on the first question is less of confident that the most factors in the problem of speaking. It considers that students have less habit to practice English in their daily life. The students don't want to explore their capability in English even though they have learned the basic structure and any else which are the components theory about English.

Based on the second questions, the best way to practice is watching movie. Watching movie is one the most interesting to study; it makes the students relax to get language stimulation by audio and visual. It can get the information in the best way without under pressure with many deadline tasks in the general system. The key is not stress. They enjoy the time and the process during watching.

The last questions, the reason that speaking is the most difficult English skills to study; the answer is speaking taking orally for the tasks. It makes sense because speaking is unique; reading, writing and listening include in one way by orally.

\section{REFERENCES}

Atkinson, D. 1987. The Mother Tongue in the Classroom: A Neglected Resource?. ELT Journal.

Brown, S and McIntyre, D. 1993. Making Sense of Teaching. Open University Press.

Eldridge, J. 1996. Code Switching in a Turkish Secondary School. ELT Journal.

Harmer, Jeremy. 2003. The Practice of English Language Teaching. England: Longman.

Harbord, J. 1992. The Use of the Mother Tongue in the Classroom. ELT Journal.

Kartika, Evie Ardya. 2016. The Effect of AudioLingual Method on the Students' Achievement in Learning Speaking Ability by the Eleventh Year Students of SMK Satria Binjai Academic 2016/2017.

Krippendorf, Klaus. 2004. Content Analysis - An Introduction to Its Maethodology. California: Sage Publication.

Wadden, $\mathrm{P}$ and McGovern, S. 1991. The Quandary of Negative Class Participation: Coming to Terms with Misbehaviour in the Language Classroom. ELT Journal. 